\title{
NEWSPAPER VIDEO CONTENT
}

\section{GENRESANDEDITORIALFORMATS IN SPAIN}

\author{
Samuel Negredo \\ Departamento de Proyectos Periodísticos \\ Facultad de Comunicación \\ Universidad de Navarra \\ 31009 Pamplona, Navarra, Spain \\ negredo@unav.es
}

\begin{abstract}
Newspaper websites and online only news operations deliver an increasingly varied and comprehensive offer of original audiovisual content. Videos on Spanish websites cover current affairs and niche interests, complementing the reports supplied by news agencies. The spoken word is a primary mode of expression, in the form of dialogues (interviews and debates) and speeches (comments and analyses), but more complex and visually appealing formats have been developed. Publishers face the challenge of organising these packages and programmes to facilitate access and retrieval. This may help to improve user experience, and to maximise long-term consumption and value.
\end{abstract}

Keywords: online video, multimedia, video journalism, news websites, audiovisual archives

\section{Introduction: New Providers of Audiovisual News on the Web}

Broadcast television organisations face new competition on the web. Online newspapers and digital only news operations are increasing their video output of news and entertainment. This is due to a number of factors. First, technological convergence has made digital video production and online distribution more affordable. Second, newsrooms have been restructured to work with and create online content, achieving what can be defined as 'business convergence.' Third, newspapers have trained or hired professionals with audiovisual production skills, which can be qualified as professional convergence. And fourth, they are now engaged in content convergence by producing video content, which is a relatively new kind of media for these organisations. ${ }^{1}$

Original video production efforts in Spanish online newspapers are predominantly aimed at short features and deal with perennial or distinctive topics, often as part of pre-formatted programmes or series. Meanwhile, footage and packages provided by agencies supply general breaking news coverage, but in the areas where there is less availability such as in local and regional news, production teams step in to supply them.

Terrestrial general interest TV channels need to engage viewers with competitive and varied schedules. This is true as well for video on offer from online newspapers that supplement news and comment videos with discovery and entertainment programmes. 
These softer content genres help to broaden the audience reach, and may attract new users to more serious and informative pieces. They are also more suitable for sponsorship than news and easier to produce.

\section{Aims and Methodology}

The main objective of this study is to test if traditional audiovisual content typologies and taxonomies are still valid for online video content. This has implications on website architecture and on the development of editorial models of original online videos.

As a consequence, there are two secondary aims: to review the options for retrieving original videos on newspaper websites, and to discuss their editorial format. This brings up a question: are complex and cohesive programmes still the norm for the online environment, or do clips that present a single topic through a single genre fit this medium better?

The work presented here is an analysis of original videos produced exclusively by or for online newspapers in Spain, which do not run an offline broadcast operation under the same brand. It therefore excludes the type of content made for broadcast and repurposed for online.

The sample for the quantitative analysis was collected over six alternate weeks in the last three months of 2011. It consists of 522 videos published by four organisations: Elpais.com $(n=105)$ and Elmundo.es $(n=161)$, the two most read news websites in Spain belonging to paid, quality, daily newspapers; Lavanguardia.com $(n=193)$, the most read newspaper website among those edited outside Madrid, and Lainformacion.com ( $n=63)$, the most read, online only news operator at the time of the survey. ${ }^{2}$ More recent examples and developments have been included in some sections for the purpose of qualitative analysis, discussion and illustration.

To complement this work, the architecture and retrieval features of the video sections on six news websites, including the four above, were tracked over four years. The results of this are presented later on.

Operationalization starts by classifying the sample videos, using standardised categories from the European Broadcasting Union Classification Scheme (EBUCore) $)^{3}$ for Content Genre and Editorial Format.

This has allowed me to put all original newspaper videos in context including news and non-news content and to take into account their topics and editorial format. This effort is also useful in determining the nature of the videos: whether they can be labelled as programmes, or whether many of them can be considered segments edited from a longer broadcast television show.

Then, I will look at site architecture and retrieval options, which determine how the user may access and experience the content on offer, using criteria related to topic, format and date, or tools such as categories, archives, playlists and search.

Last but not least, I will analyse briefly the editorial models of the most production-intensive news formats on offer through the years: daily and weekly video news bulletins and news magazines repurposed for the web or produced entirely for this medium.

2 Videos from Lainformacion.com are not discussed here due to space limitations, the small sample, and because the site ceased original video production when it merged with another company, and has been superseded in the rankings by several other web-native brands. Some of its most remarkable works are La Plaza: la gestación del movimiento $15 \mathrm{M}$ and EI mal del cerebro, big-scale documentary productions that went live in early 2012, in the months following the data collection for analysis.

3 EBU, EBU Core Metadata Set, version 1.5, 04/2014, https://tech.ebu.ch/docs/tech/tech3293v1_5.pdf, (Retrieved: 1 December 2014). 


\section{Content Genre: News and Current Affairs Videos supplemented with Arts, Lifestyle and Other Categories}

The Content Genre classification broadly describes the topic of videos according to the main categories in the EBUCore, ${ }^{4}$ which was adapted for this study, in order to keep a single hierarchical level. ${ }^{5}$

News or pure information was the most popular topic category on all three sites, but qualitative differences are important. It represented $50 \%$ of the videos by El País, many of them being comments and analysis about the news rather than actual reporting; $45 \%$ of the videos in La Vanguardia had a very high proportion of local on-site newsgathering, and $31 \%$ in El Mundo represented slightly longer features covering events happening in Spain.

Let us now turn to the results of the other categories for each website. In Elpais.com, Sciences (11\%), Humanities $(10 \%)$, the Arts $(9 \%)$ and Music performances $(8 \%)$ were the four most popular content genre categories. A reason for this is the existence of niche programmes and special series, as I will discuss in the next section.

Twenty seven per cent of videos on Elmundo.es covered leisure, hobbies, consumer and lifestyle issues, almost reaching the same output as News and factual content. Within this category, users can find a great variety of videos.

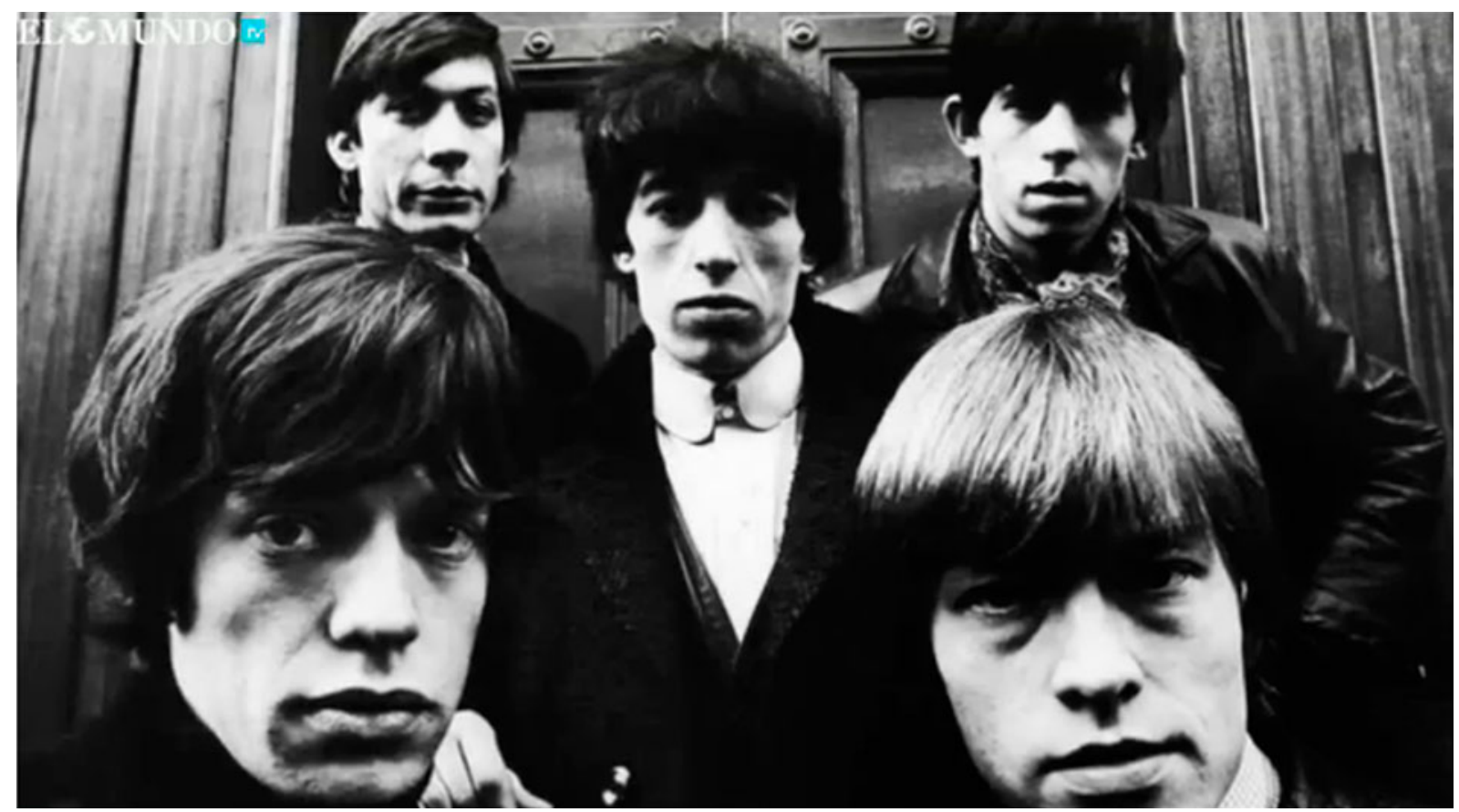

Video 1. Click here to watch it.

Title: El Mundo. Miradas al Fresco. Terry O'Neill interview

Description: The Miradas al fresco (Fresco glances) series from El Mundo highlights art exhibits with commentary from painters, photographers and curators. This example is representative of the broad arts and culture coverage offered in video by the newspaper. Language: Spanish.

4 EBU, European Broadcasting Union Classification Scheme: Content Genre, 20 August 2010, http://www.ebu.ch/metadata/cs/web/ebu_Content GenreCS_Mapping_p.xml.html, (Retrieved: 1 December 2014).

5 Only an Economy category was added in order to better quantify the content on this topic that was not strictly linked to current affairs. The categories are as follows: 0) news or factual content ; 1) non-fiction; 2) Arts; 3) Humanities; 4) Sciences; 5) human interest; 6) transport and communications; 7) events; 8) media; 9) sports; 10) fiction or drama; 11) amusement, contest or entertainment; 12) music; 130 interactive games; 14) leisure, hobby, consumer or lifestyle; 15) economy or business; 16) other. 
dealing with consumer technology, food and drinks, fashion, property, interior design, and similar themes. The Arts (9\%) were a distant third (e.g. such as the weekly series about paintings, Miradas al fresco), followed by Sciences and Humanities ( $7 \%$ each), and Music (6\%).

As for the rest of original video production on Lavanguardia.com, leisure, hobby, consumer or lifestyle content was also the second most popular category $(11 \%)$, including videos about travel, food, trends and technology. Economy $(9 \%)$ made it into the top 3, due to the fact that there was a new video blog on this subject every weekday. Eight per cent of the original videos belonged to the music genre; for instance, Acustik has been showing a live performance every week since June $2010,{ }^{6}$ and many interviews with artists were offered during the six observed weeks. Seven per cent of the videos dealt with the rest of the Arts.

\section{Editorial Formats in Original Online Video: News Reports, Features and Talks}

The editorial format classification reflects the most general categories ${ }^{7}$ included in the European Broadcasting Union code for labelling the editorial format of programmes. ${ }^{8}$

In the analysis, individual packages, such as generic news reports and features were classified under the 'none' category, in order to distinguish them from news programmes, which would be classified as 'bulletins.' As a consequence, the 'none' category was the most frequent on the sites with many standalone news reports and features, such Elmundo.es and Lavanguardia.com.

I will argue in the conclusions that this shows that the traditional broadcast classification code is not completely suitable for original online newspaper video, as many pieces of content are single genre and single topic units, instead of the traditional formats comprising several genres and topics to be found in broadcast television practice.

Comment and critique videos were classified under 'lecture, speech or presentation,' and any dialogue-based piece was coded as 'discussion, interview, debate or talk show.'

Many of the original videos on Elpais.com were speech-based at the time of the study. Almost one third (32\%) were talks directly to camera, such as La voz de Iñaki. This is a video blog covering politics on weekdays since April 2011, and has been the only original programme on offer on a daily basis, from Monday to Thursday. ${ }^{9}$

Twenty five per cent of the original videos on El País were classified under the 'discussion, interview, debate or talk show' category. The sample comprises of interview-style political analyses and debates, and were recorded in the Guadalajara book fair. Another $25 \%$ related to non-programmes: hard news and reportage. Incidentally, $10 \%$ of the videos were counted as 'contest,' as the site carried the maths challenge El desafío matemático.

6 Lavanguardia.com, 'Tres años de Acustik,' 18 June 2013, http://www.lavanguardia.com/musica/20130618/54375733409/tres-anos-de-acustik. html, (Retrieved: 1 December 2014).

7 Interactive television categories were dismissed for this study, as there were no videos in the sample with those features. These are the categories used in the analysis: 0) none; 1) bulletin; 2) magazine; 3) event; 4) documentary; 5) discussion, interview, debate or talk show; 6) lecture, speech or presentation; 7) textual; 8) user participation or phone-in; 9) docusoap; 10) reality; 11) religious; 12) animation; 130 show or contest; 14) comedy; 15) reality show; 16) artistic performance; 17) other.

8 EBU, European Broadcasting Union Classification Scheme: Editorial Format Code, 20 August 2010, http://www.ebu.ch/metadata/cs/web/ ebu_EditorialFormatCodeCS_Mapping_p.xml.html, (Retrieved: 1 December 2014).

9 La Voz de Iñaki is led by one of the most respected journalists in Spain, Iñaki Gabilondo, and it is published simultaneously on the websites of newspaper El País and its sister radio network Cadena SER as an audio feed at $9.05 \mathrm{am}$. 


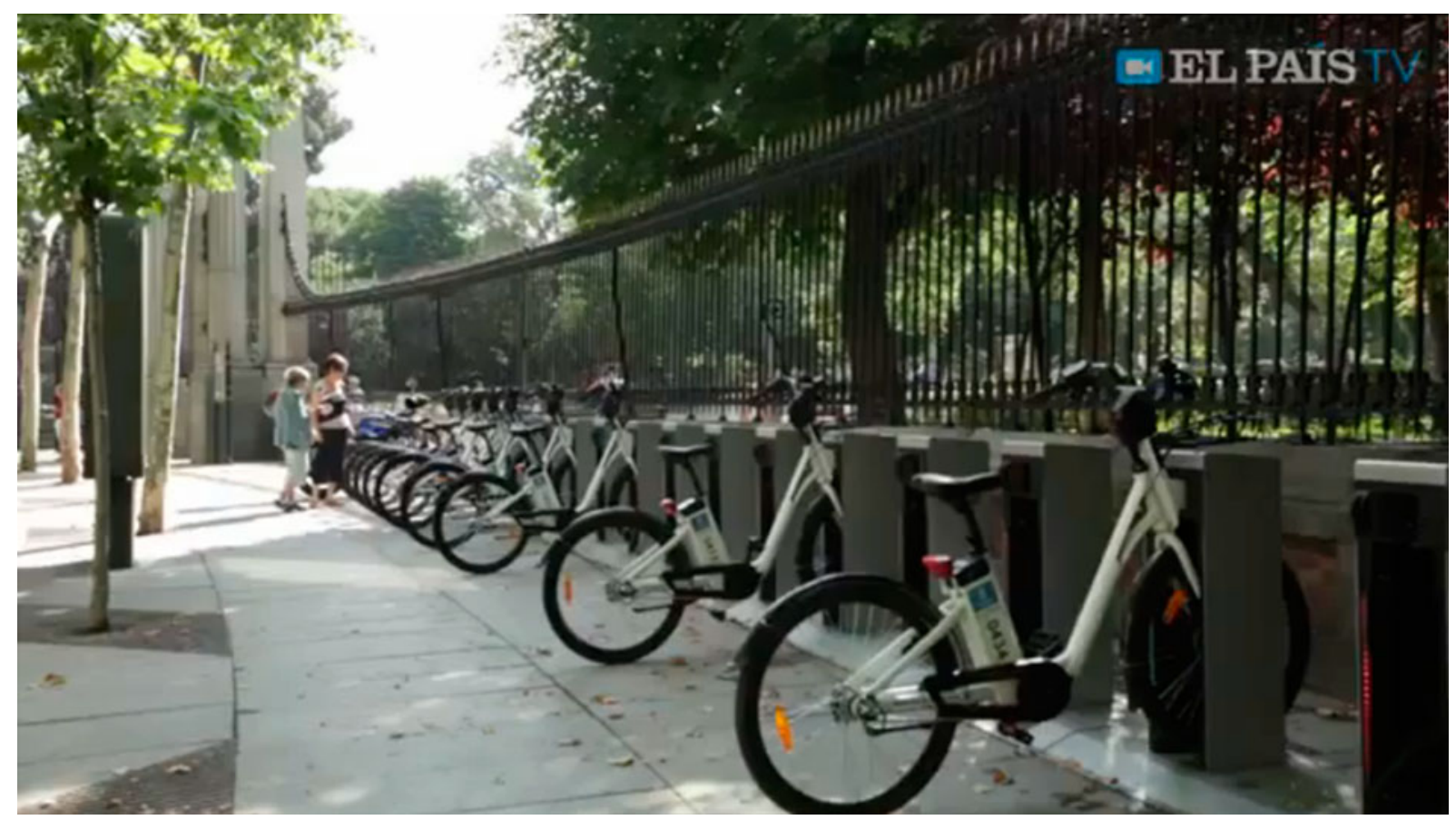

Video 2. Click here to watch it.

Title: El País. Los pedales de la discordia

Description: This 3-minute video covers the launch of a public bike rental scheme in Madrid. The format, a feature with high production values and innovative techniques, is a typical one for the video team at El Pais. A specialist reporter is involved.

Language: Spanish

Fifty four per cent of Elmundo.es videos were news reports or longer features and packages; among the latter, the video blog La trinchera was usually updated several times a week and has been doing so for three and a half years. After the study was conducted, during the first semester of 2013, Dossier covered one topic in depth every month.

Twenty four of the videos were conversation led on Elmundo.es; for example, artists and politicians were interviewed in cafés for the series En la barra con... Just $11 \%$ of the clips consisted exclusively of talks delivered to camera, as in the video blog Dos minutos en el mundo. It is published on Saturdays and started in 2011. The format has evolved for the sake of visual variety and appeal: the comments are now recorded on location in Madrid instead of inside the newsroom, and is reinforced with agency and file footage.

Elmundo.es also offered several kinds of animation: both political humour cartoons, such as Moncloa Palace and 3Dmodelled infographics in its Especiales. Street music performances, short documentaries, and a few magazine and phone-in programmes are also part of El Mundo TV. ${ }^{10}$

Among the original videos published on Lavanguardia.com during the observed weeks, $53 \%$ were standard news reports or short features, linked to daily current affairs coverage. They are archived under the Actualidad or Barcelona sections in the video area of the website. Fifteen of the videos were interviews, for which there is a specific Entrevista channel.

An additional $1 \%$ belonged to user participation in the live Q\&A programme Chat TV, each monthly episode going on for approximately half an hour. Talks, such as those in video blogs about the economy, made $10 \%$ of the original production items. 
No less than $11 \%$ of Lavanguardia.com videos could be classified as magazine programmes. These productions go beyond standard genres such as reports and interviews, by adding short additional segments or original twists to how the topic is covered. The internal production and multimedia team at Lavanguardia.com has been developing new ideas and formats for programmes since 2007. They are usually published at weekly or monthly intervals, and sometimes they are discontinued or put to rest temporarily, depending on production costs and audience reception. Other programmes, such as the travel show MelarGO, do not follow a fixed publishing schedule. ${ }^{11}$

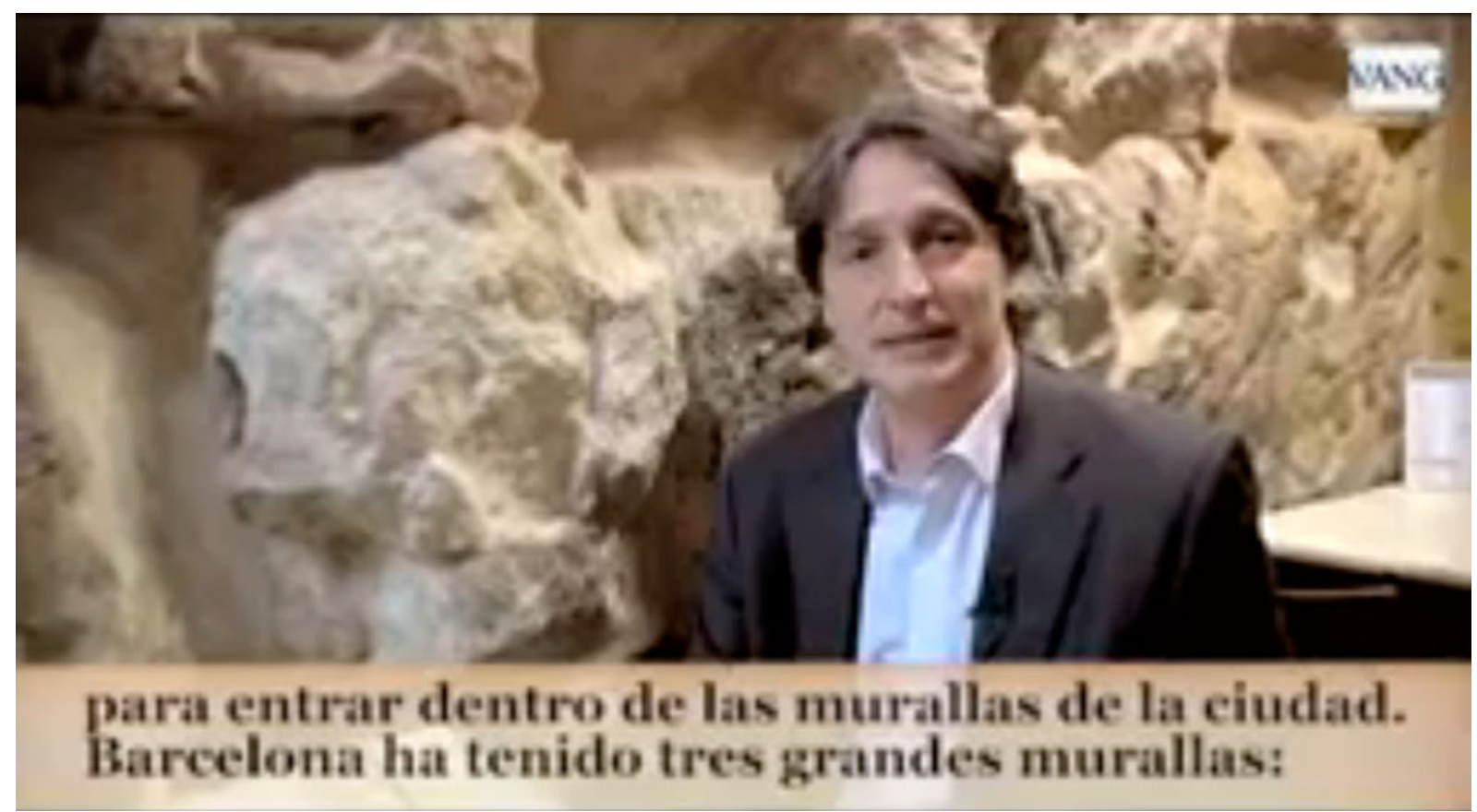

Video 3. Click here to watch it.

Title: La Vanguardia. Històries de Can Fanga. Salve, Barcino!

Description: In this show from La Vanguardia, historian Pere Portabella teaches about the history of Barcelona. This episode, recorded on location, shows the Roman walls in the city using post-production techniques.

Language: Catalan with Spanish subtitles.

Other editorial formats found on Lavanguardia.com videos are music performances (3\%) and animation (3\%). They used to host custom made cartoons and later went for the increasingly popular genre of animated graphics, and short documentary series, such as the eleven-episode Groenlandia: misión Aurora.

\section{Site Architecture: Disjointed Archives and Hard to Retrieve Videos}

To maximise the value of original video productions in the medium to long term requires specific information about architecture features and retrieval tools that not all online news sites have yet incorporated into their video sections. 
It has just been demonstrated that classifications made for TV are still operational for most original online news and current affairs videos and for the other non-news productions that complement them, even if there are some adjustments to be implemented.

Most publishers use metadata extensively already to manage and search their collections. This resource should also be made available to the public, so that they will be able to retrieve the sequences they are looking for, and not only see the latest uploads.

Wherever possible, to maximise long-term value, the programme pages, sections and collections should be better integrated. Publishers should not have to resort to uploading to platforms such as YouTube or Vimeo to showcase their portfolio of formats and programmes, or rely on these services to make their videos findable, shareable and embeddable. As part of the analysis, the evolution of user-facing videos on the main five newspaper websites in Spain (Elpais.com, Elmundo.es, Lavanguardia.com, 20minutos.es and ABC.es) and that of a pure player (Lainformacion.com) has been observed during a four-year period, tracking the availability of four basic classification and retrieval features. These enable the user to navigate the videos more easily as they are archived by date, search, browsable categories, and playlists for programmes or series.

At the time of writing, none of the six websites offered a calendar-based archive in their video section; El País and La Vanguardia used to do so in mid-2010, but they both discontinued it.

All of them offer specific video search, except for El Pais, which did away with this feature when a new version of the site went live in February 2012.

Neither El País nor El Mundo provide the option to browse videos by category when their sites were relaunched, even though it was available before.

The option to retrieve other videos from a specific series or programme is only available on Lavanguardia.com and in 20minutos.es. Other sites, such as El País and El Mundo, fall back on custom made packages, blogs or sidebar modules for this basic archival feature, or they just use tags that are not specific to this kind of media.

\section{Watchingthe News Online}

\subsection{Repurposing Broadcast News forthe Web}

Video can be considered to be the natural medium for broadcasters to expand their online news presence, but the home pages of the websites for the main television newscasts in Spain replicate the structure of online newspapers; they just display a list of headlines, some of them linking to text stories, and others leading to pages that do feature video. Almost all broadcast news programmes are available to watch online in full, but very few additional options are offered to access the content in a non-linear way or to share parts of it.

However, broadcasters have developed a more dynamic strategy in the business-to-business front: Telecinco was quick to identify a market opportunity and has offered its news videos to other online publishers through the Atlas agency since the mid-2000s. Its main commercial competitor, Antena 3, took the same approach with VNews, which was later sold to an external production company. The largest traditional news agencies in Spain, EFE and Europa Press, also provide news clips for online media, and Reuters videos are available through its partnership with Live!, a Spanish video streaming venture.

Individual reports or fragments of newscasts are uploaded directly, either before of after broadcast. The only adaptation is to add fields such as a title, a description, credits or tags. This is standard practice, but some projects have adapted to producing a headline summary, repurposing content or developing web-native formats. 
El informativo en la Red was produced by rolling news channel CNN+. It operated with some difficulties from November 2000 until the channel closed permanently in December $2010 .^{12}$ Through the years, this online only bulletin was published on Plus.es, an early content-rich portal associated with the satellite platform CNNplus.com, Elpais.com, and Cuatro.com, the online environement of a terrestrial channel. A comprehensive archive is not currently available.

The staff and technical resources used for the bulletin were those of the broadcast network; the difference consisted in the mode of address and transmission. Technology affected the format too: at first, the standard on-screen broadcast graphics were avoided, as low-bandwidth compression made them unreadable. The videos consisted of a welcome message, a typical top-of-the-hour headline summary, and an image-driven story similar to the And finally... segments in standard newscasts, followed by a short farewell.

The Catalan public broadcaster launched TV3minuts in January $2008 .{ }^{13}$ It offered free-to-access, carefully edited threeminute video summaries of its main shows, including every daily news and current affairs programme. ${ }^{14}$ That very November, on-demand video service TV3alacarta dropped the freemium ${ }^{15}$ model it had started with in $2004,{ }^{16}$ and it became supported by advertisement only. Therefore, news and current affairs programmes became available on demand, and the summary service was suspended at the end of the year.

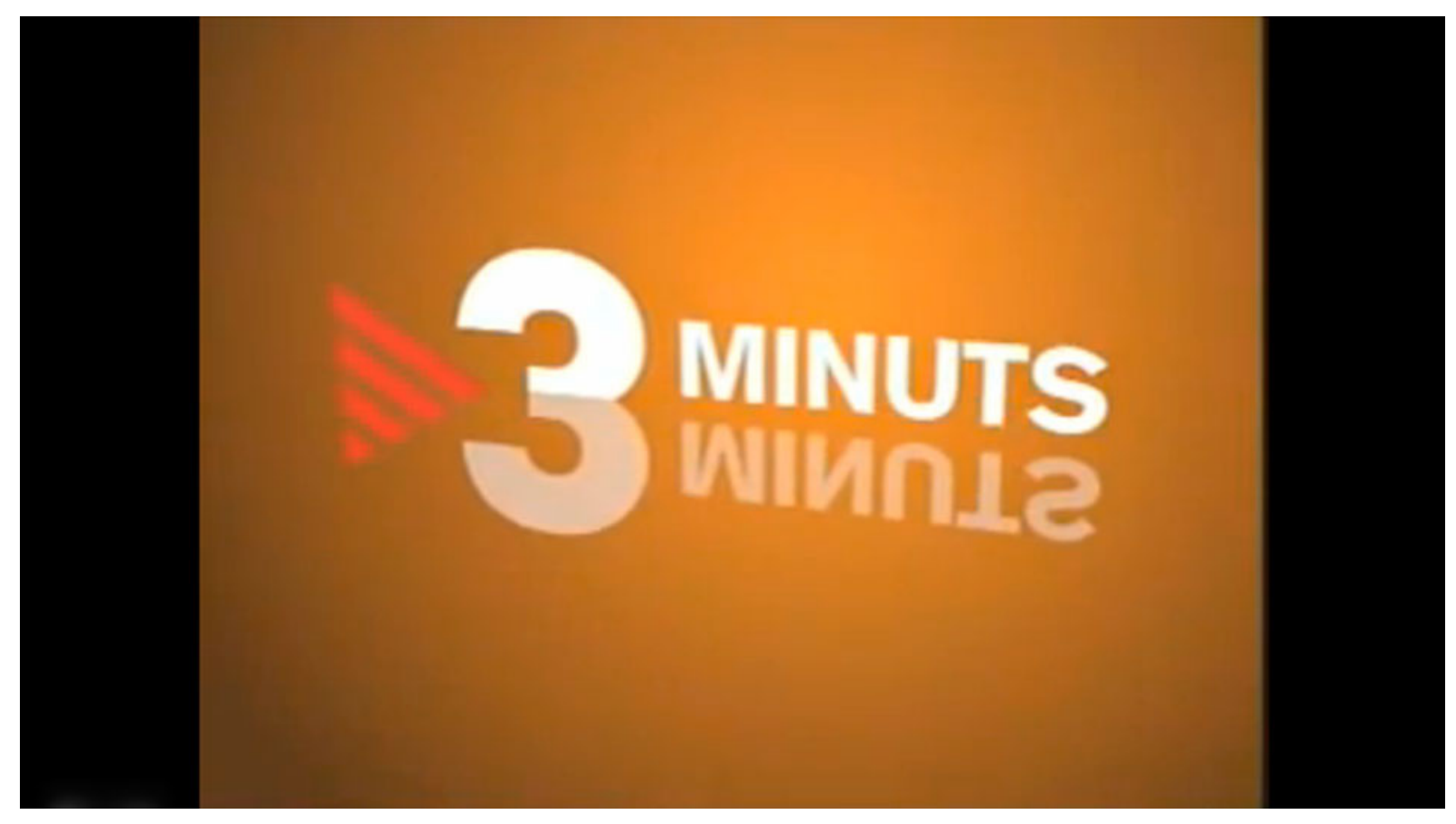

Video 4. Click here to watch it.

Title: TV3-TV3minuts promo.

Description: "You now have a 3-minute summary of the most-watched TV3 programmes on your phone, on the website or on podcast." Language: Catalan.

12 El País, 'ELPAIS.es ofrece dos informativos producidos por CNN+ para Internet,' 8 October 2001, http://elpais.com/diario/2001/10/08/sociedad/ 1002492006_850215.html, (Retrieved: 1 December 2014).

13 TV3.cat, 'TV3 ha posat en marxa el servei TV3minuts,' 21 January 2008, http://www.tv3.cat/actualitat/48240/TV3-ha-posat-en-marxa-el-serveiTV3minuts, (Retrieved: 1 December 2014).

14 An archive is available by searching for TV3minuts in http://www.tv3.cat/videos

15 The term freemium describes business models that offer limited access for free - it may be limited in time, quantity or quality - and require a one-off or an ongoing payment for full access.

16 TV3.cat, 'TV3alacarta - Preguntes més freqüents,' http://www.tv3.cat/3alacarta/faqs.htm, (Retrieved: 1 December 2014). 
Telediario en 4 minutos is one of the most popular and most prominently promoted news video items of public broadcaster RTVE since its online relaunch in summer 2008. The four-minute format is nothing else than the opening summary of the morning, afternoon and evening newscasts. This is similar to the One-minute World News from the BBC, which is just a recording of the headline summary that airs at half past the hour on the BBC World News channel.

And finally, it should be noted that commercial channel laSexta used to upload the newscasts to its website with a playlist feature that enabled users to watch them in full or to jump to specific stories or segments in the running order. The practice was abandoned when the merger with Antena 3 came into practice, as they now share a common player for all programmes.

\subsection{Original Daily and Weekly Programmes for Websites}

I have just discussed the ways in which television newscasts have been repurposed for on-demand online consumption. In parallel, many websites have developed distinctive and original video news programmes, with varied formats and strategies.

International examples can be found easily: The New York Times launched, diversified and eventually shut down TimesCast, and The Washington Post started up The Fold, but later did away with it as it continued to expand its video offerings. ${ }^{17}$ Similar experiences from the Spanish market are now presented here.

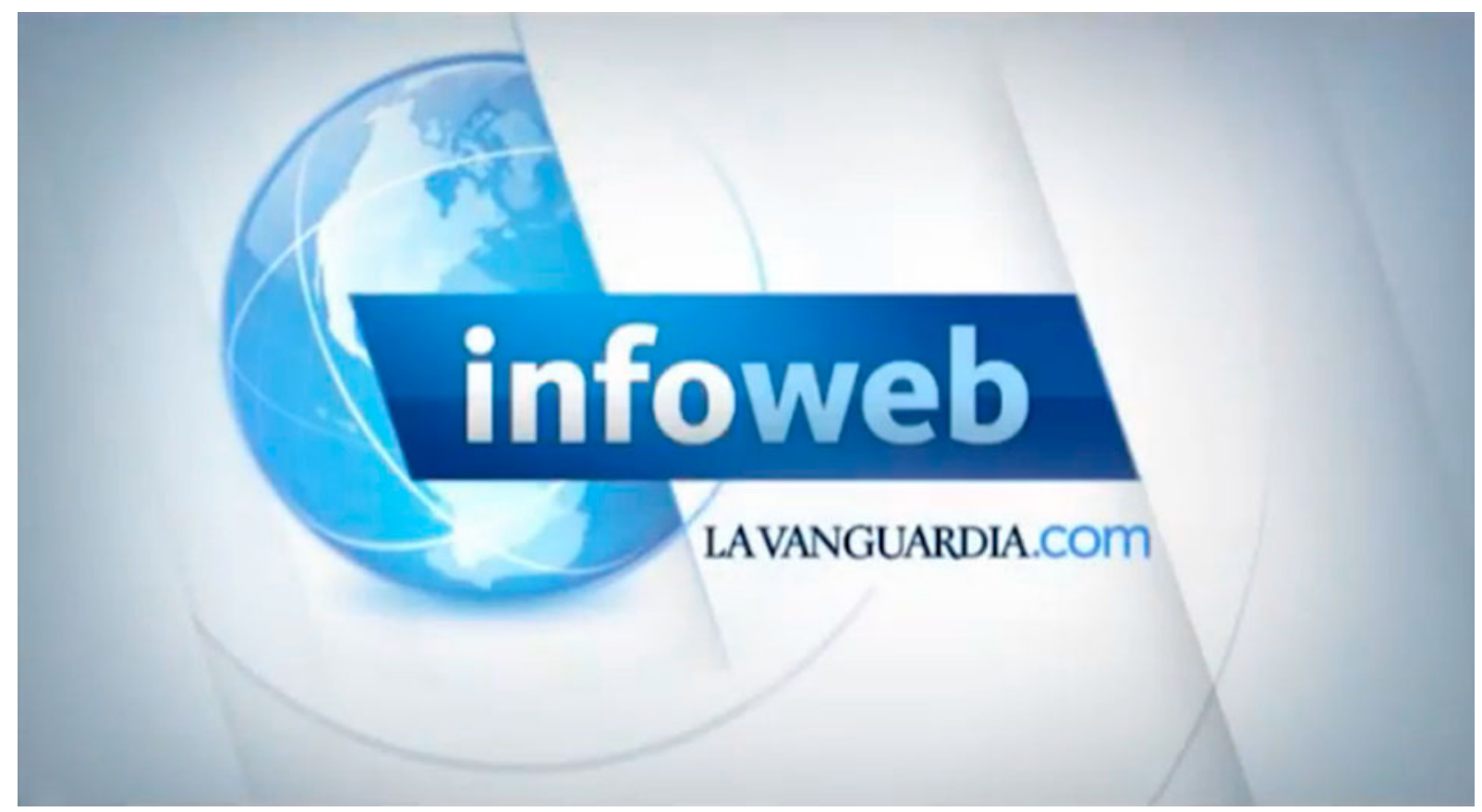

Video 5. Click here to watch it.

Title: La Vanguardia - Infoweb - Farewell to Adolfo Suárez

Description: An edition of the long-running weekly news, participation and cross-promotion show from La Vanguardia, the last one before it was discontinued. Presented by Sílvia Colomé, head of video and multimedia production.

Language: Spanish.

17 Dylan Byers, 'Why live video won't save the news biz,' Politico.com, 24 February 2014, http://www.politico.com/story/2014/02/live-video-wontsave-news-business-103819.html, (Retrieved: 1 December 2014). 
Coincidentally or not, the first three formats I will discuss are or were presented on screen by a female journalist. The now defunct site ADN.es, which launched in 2007, put together for some time a web-native daily video bulletin. It used to be uploaded in the afternoon, under the title $A D N p m .{ }^{18}$

In Catalonia, Lavanguardia.com produced Infoweb every Friday from September 2010 to March 2014, showcasing the most popular news and video content on the website, the best user contributions, upcoming productions and live video events, all in just around four minutes. ${ }^{19}$

Its direct competitor, Elperiodico.com, continues to offer L'informatiu every afternoon Monday to Friday since April $2012 .^{20}$ The structure is more conventional, with duration of five minutes.

During the early 2010s, Elmundo.es developed a model in which daily audiovisual analyses were kept for the enhanced digital newsstand edition of the print newspaper. The website posted its own videos on local news, features and lifestyle, and relied mostly on the agencies for hard news footage and sound bites. This started to change in April 2013: LaSemana.zip was launched as a studio based weekly summary, published early on Saturdays, with video recaps and two-way interviews.

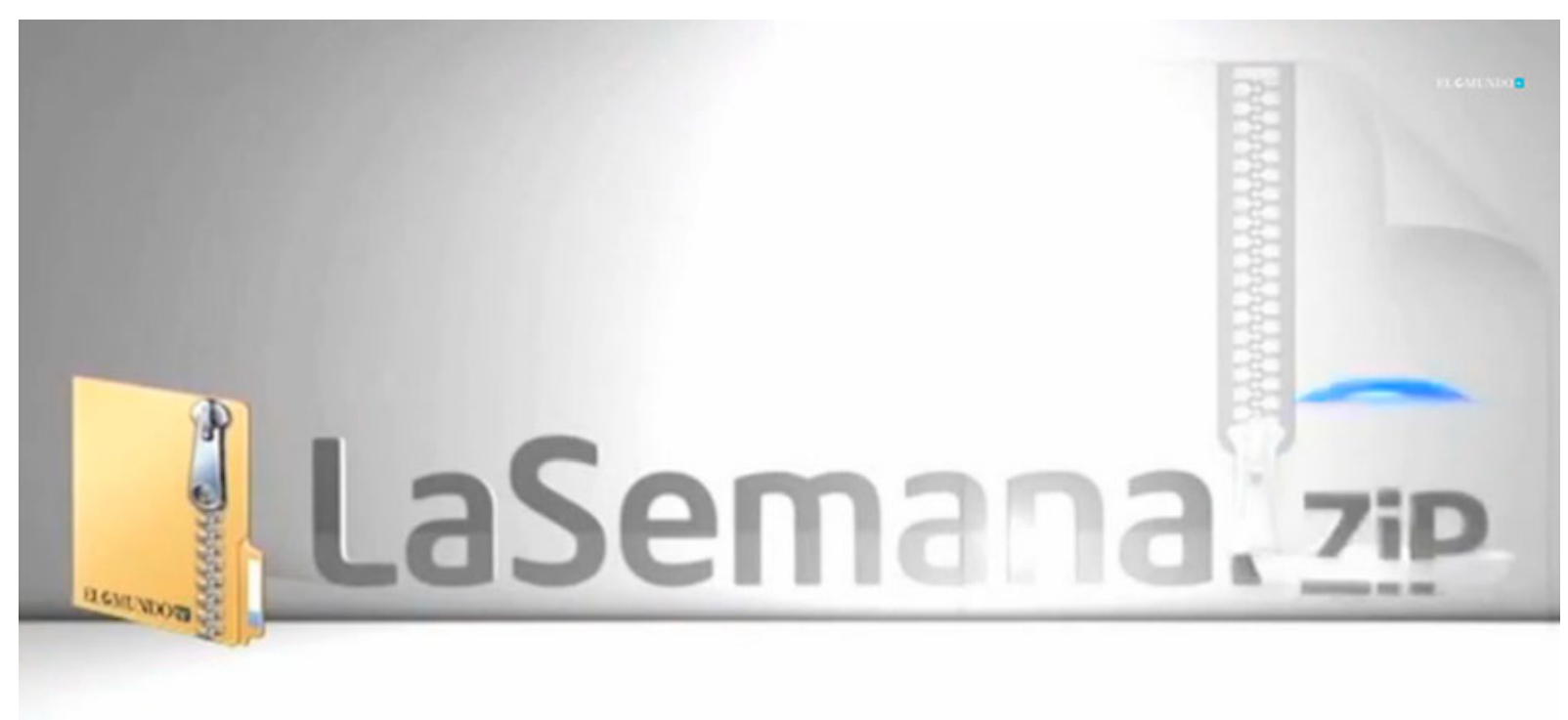

Video 6. Click here to watch it.

Title: El Mundo.LaSemana.zip

Description: The weekly summary of the news and other video content from El Mundo, fronted by producer Cristina de Rojas on Saturday mornings. Featuring an infographics explainer from $3.40 \mathrm{sec}$, presented by the editor of the programme, Mario Viciosa. Language: Spanish.

18 No episodes are currently available online. ADN.es stopped operating as an independent news operation in January 2009, and the publishing company erased most of its online presence, including external sites, after it closed completely in 2011.

19 Lavanguardia.com, 'La Vanguardia.es estrena 'Infoweb', un nuevo concepto de informativo on line,' 17 September 2010, http://www. lavanguardia.com/internet/20100917/54005013722/la-vanguardia-es-estrena-infoweb-un-nuevo-concepto-de-informativo-on-line.html, (Retrieved: 1 December 2014).

20 Elperiodico.com, 'EL PERIÓDICO estrena hoy un teleinformativo para móvil y web,' 16 April 2012, http://www.elperiodico.com/es/noticias/ sociedad/periodico-estrena-hoy-teleinformativo-para-movil-web-1666444, (Retrieved: 1 December 2014). It was originally titled El informativo, but it switched from Spanish to Catalan soon. Full editions of the newspaper and the website are published in both languages. 
Elmundo.es added El Mundo en 90" in June 2014. It is a (roughly) 90-second bulletin with a voiceover but no on-screen presentation. It is updated twice daily, at 13.30 and $19.00 .^{21}$ Text links to every story mentioned in the bulletin are included below the video player. ${ }^{22}$

A brief digression has to be made here to include La Tuerka, a leftwing political debate with a considerable following, which evolved from a weekly edition on local television to four 90-minute episodes per week since December 2013. The programme was to be streamed live from the newsroom of the news website Público.es, with full archives available online. ${ }^{23}$ Emerging politician Pablo Iglesias created it and fronted it at first; he later took turns with other presenters, and the team developed the programme further for the season starting in October 2014. They increased format diversity by adding reportage and humour.

A valuable addition to the format of the original online newscast happened in March 2014, when Catalan newspaper site Ara.cat launched a daily (Monday to Thursday) programme, edited and presented by renowned journalist Antoni

Bassas. AraBassas was streamed live at 20.00 hours, and was made available on demand right after, in full and split in clips.

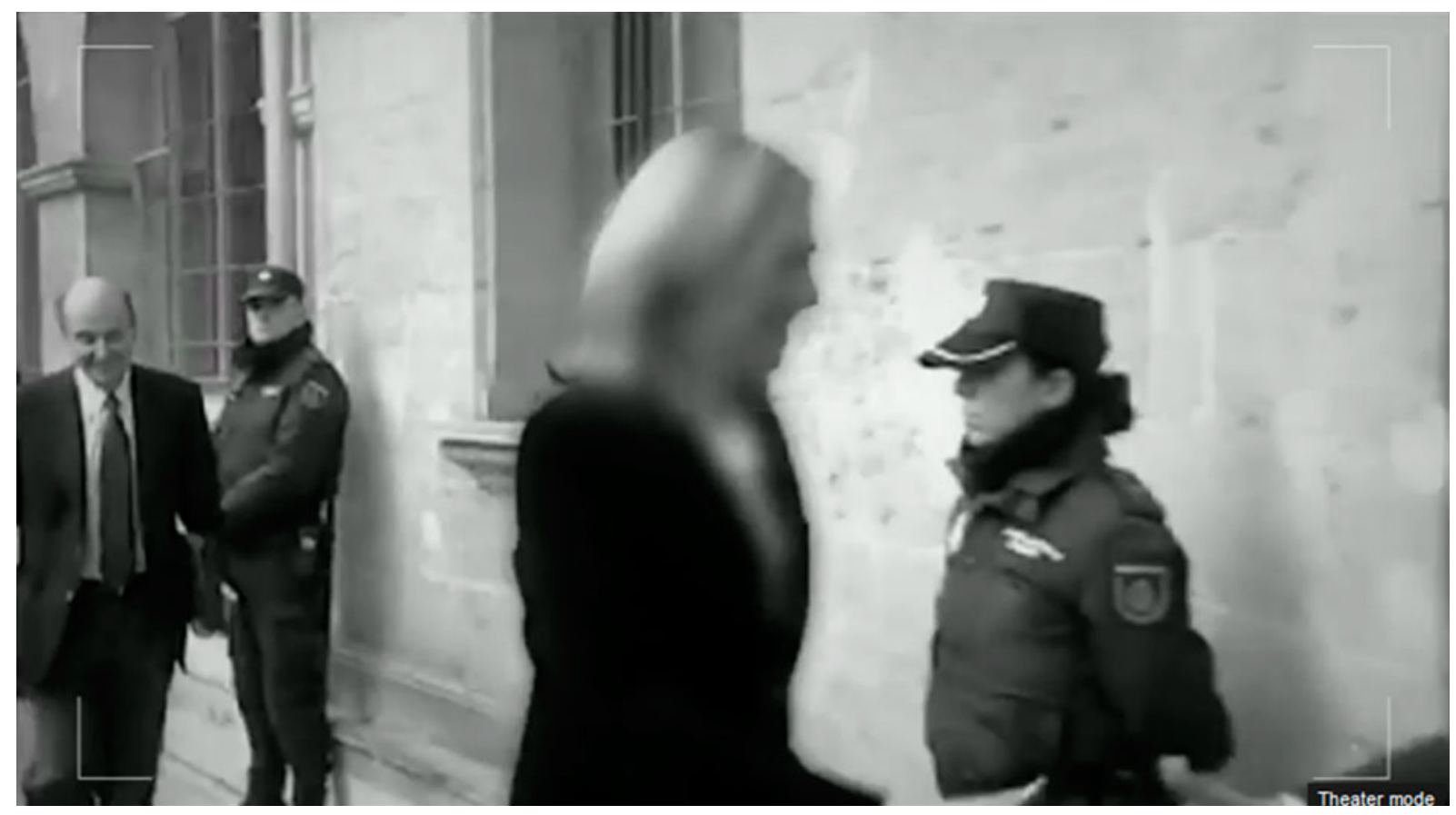

Video 7. Click here to watch it.

Title: Diari Ara.AraBassas.Launch promo

Description: "Journalism that will make everything clear for you is back." With Antoni Bassas. Language: Catalan.

Daily sections in AraBassas encompassed an editorial opening, a summary read by a female co-presenter, stand-up debriefing interviews from the newsroom, a quick fix of the news in 60 seconds as covered on television, and in-studio and on-location interviews, which were supplemented with sporadic appearances by a range of columnists, and other

21 El informativo en la red by $\mathrm{CNN}+$, which is mentioned above, also consisted of two daily editions, which were published at similar times: 13.30 and 19.30 hours.

22 As it has been explained, no browsable archives are automatically available for Elmundo.es programmes, so archival content can only be retrieved by search.

23 Público.es, 'PúblicoTV, nuevo cuartel general de 'La Tuerka”, 29 November 2013, http://www.publico.es/485682/publicotv-nuevo-cuartelgeneral-de-la-tuerka, (Retrieved: 1 December 2014). 
specialised segments. The running time of this ambitious and appealing daily programme usually ranged between 20 and 30 minutes during the first season, doubling the 12 minutes that were initially advertised.

The format was scaled down and split up in September 2014, allowing for more flexibility. The editorial comment is delivered much earlier, at $10.00 \mathrm{am}$, and an After Work entertainment segment is uploaded in the afternoon. Only a few of the original sections remain; this allows the newspaper to add video analysis of breaking news, interviews and longer debates during the day, when needed.

\section{Conclusions}

This analysis shows that the repertoires of categories that are used to classify units of content in broadcast television according to their content genre and editorial format need to be revised if they are to be applied to online video. The reason is that single genre and single topic units of news content, and standalone segments, coexist with more complex formats and programmes, which comprise several genres and may cover more topics.

From the first quick headline recaps repurposed from television in the 2000s, to current comprehensive original online video selections, what newspapers provide online has come a long way. In the current Spanish market, the great political, geographical and language diversity results in a diverse audience to address.

Users and researchers can now find original online videos reporting local news from the ground up, documentaries knowledge and discovery formats, and newscasts and current affairs programmes that reflect on the events of the day or of the week. Online video is already a platform for debate, offering alternative perspectives, and coverage that does not fit in broadcast television.

Access to this content should not be limited, but enabled and made easier by user-friendly site architecture. The challenge of making this content more findable online and in the long term is still unresolved by some publishers, while others have already addressed these retrieval problems and are working on providing more immersive and ubiquitous experiences that keep users engaged.

Additionally, questions need to be answered about how viewers prefer to experience online content.

Based on the analysis in this article, it can be suggested that within the area of branded and personality-led news formats, there is an evolution towards on-demand and fragmented selections. They minimise format constraints and are designed to combine opinion and entertainment segments delivered at fixed times every day, along with reactive news reports, analysis and discussions. In brief, it can be stated that, as online video news formats evolve, they are not constrained by schedule or time (of broadcast) as with traditional broadcasts. This results in a more efficient and reactive production.

\section{Bi ograph y}

Samuel Negredo holds a PhD in Communication (2013) and an MA in Online Journalism (2011). He has been monitoring original video production for the web by news organisations since 2008. He is Assistant Professor at the Journalism Department of the University of Navarra. He has taken part in two competitive state-funded research projects on convergence and innovation in the Spanish media market, and co-authored the book Integrated Journalism (2009). He has also published articles on user participation in news production and distribution and on forms of interactivity and content presentation in European web documentaries. 